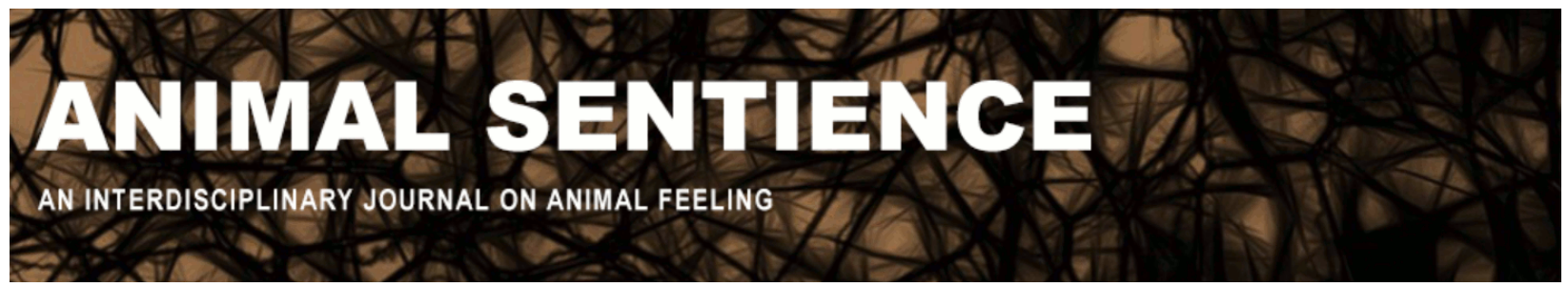

Mather, Jennifer A. (2019) What and where is an octopus's mind?. Animal Sentience 26(26)

DOI: $10.51291 / 2377-7478.1528$

Date of submission: 2019-10-05

Date of acceptance: 2019-12-14 (c) 


\title{
What and where is an octopus's mind?
}

Response to Commentary on Mather on Octopus Mind

\author{
Jennifer A. Mather \\ Department of Psychology, University of Lethbridge
}

\begin{abstract}
It is gratifying to see the thorough discussion of whether octopuses have a mind, though perhaps a mind that is different from those of "higher" vertebrates. It stimulates us to look at the welfare of these animals and challenges us to find better ways to test mindfulness and cognition across animals with widely differing natural histories and sensory and motor capacities.
\end{abstract}

Jennifer Mather is Professor in the Department of Psychology, University of Lethbridge. She has published many articles on cephalopod behavior and intelligence and is regarded as an authority on ethics with regard to cephalopods. Website

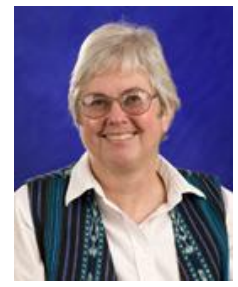

1. Introduction. Behavior is expressed by the whole animal, not smaller and smaller components. That is what fascinated me about animal behavior in the first place. I completed my doctoral work in human perception; one of the lessons of the Gestalt psychologists was that "the whole can be more than the sum of its parts". What I took this to mean practically is that the whole animal controls and expresses behavior and the whole animal is programmed by its mind. Reproductive strategies, for example, are undoubtedly urged on by hormone levels and guided by information received by the brain; but they also result from assessing the competition, the quality of potential mates, the likelihood of a better choice, or that a dominant individual is watching. We need to know how behavior and the mind are the result of combinations of its component pieces, but we have to start with the whole.

2. Can we have a complete and agreed-upon definition of mind? Several commentators suggest that I operationalize the contents of my discussion: Mallatt says the key terms were not defined; Correia Caeiro asks for operational definitions. Some propose a definition: King \& Marino that animals "reason about how to negotiate the world around them and respond flexibly", Mallatt that they can "adjust their behavior to solve problems, to learn a lot, to explore and play", and Porcher, at greater length, that "octopuses have an 'I', a self-serving awareness or consciousness controlling the manipulation of the mental concepts, making moment to moment decisions about the proceedings and keeping its goals in mind as it pursues life". According to Corcoran, "minded organisms are ... actively sampling and interrogating their environment to procure informative sensory data".

Dictionaries, which tend to be human-centered, are not a lot of help. Collins says "your mind is your ability to think and reason", Merriam-Webster that it is "the organized conscious and unconscious mental activity of an organism". No one definition will make everyone happy, but taking advice from these sources and systematizing my discussion, I would define mind as "the entity which controls behavior of an organism - not just taking in and storing 
information but seeking it (as in exploration and play), organizing it, and flexibly using it in choice and control of output". This definition emphasizes that minds are active in all three areas - input seeking, organization and output planning — and see Mather's (2019) Figure 1. It reminds me of Shettleworth's (2010) definition of cognition, as "the mechanisms by which animals acquire, process, store, and act on information from the environment", though I would specify that this includes the internal as well as the external environment, so perhaps minds "do" cognition, though they may do more than that.

3. Do we need to postulate a mind for octopuses? Several commentators are more comfortable with a simpler explanation of behavior. Mehrkam believes that there is a more parsimonious explanation of these capacities and that operant behavior can produce the variety of abilities that octopuses demonstrate, but that would still not account for information seeking). Ginsberg and Jablonka (2019) suggest that sentience is the evolutionary result of Unlimited Associative Learning, but that too may be too narrow. Learning theories do not explain the drive to acquire information. Corcoran's well-presented explanation suggests that information-seeking behavior, which does not seem to result in overt learning, is instead driven by the need to gain data that will fuel creative solutions to novel future problems. This counters Gutfreund, who thinks that we only interpret simple trial-and-error learning by animals as the cause of something more complex because our assessment of animal cognitive abilities is "observer-dependent". The simplest explanation for actions is not necessarily the correct one; isolating small steps of a complex process in a laboratory setting may lose the context in which they were expressed. Amodio admonishes us to be "agnostic" about our assumptions, but if you make no hypotheses, you cannot test them. Schnell \& Valloritgara are uncomfortable with the term "mind". They see it as an immeasurable concept, preferring instead to be guided by mechanistic accounts and underlying neural processes. Yet the Gestalt psychologists remind us that studying the component pieces will not necessarily help us understand the whole; a controlling "mind" may be "ill-defined" yet still there.

4. Where is the octopus mind? The need to evaluate whether the octopus mind is unified arises because its nervous system appears to be so physically distributed. It is an oft-quoted fact that 3/5 of the octopus's neurons are in the arms, not in the brain. There also appears to be no somatotopic representation of the periphery in the brain. This led Grasso (2014) to suggest that octopuses have "two brains", with a somatosensory representation manufactured by the whole arm neural complex. There is no doubt that much lower-level processing is carried on by the chains of brachial ganglia. Schwartz - based on his mistaken belief that Wells (1978) had found that octopus arms could be conditioned independently of each other - concludes that the octopus system is a "community of independent minds" because of this peripheral processing. This is echoed by Favela, who says that the octopus has multiple systems and possibly multiple Umwelten rather than a single Umwelt. CarlsDiamante (2017) has also suggested that consciousness in the octopus may need to be seen as distributed. Yet there is no evidence of higher-level processing in this complex of ganglia, just lower-level sensory-motor adjustment. Godfrey-Smith is less sure of peripheral "minds". He believes that octopuses might have a single "self" and that attention can "pull together" the animal, but that arm motions may be semi-autonomous. Gutnick et al.'s (2011) studies show that the octopus brain can indeed learn cues from vision for arm actions and it 
can dictate arm motions. We need to remember that the extensive neural processing in the arms is used for controlling the complex set of muscles in the boneless muscular hydrostat movement system (Kier and Smith, 1985), not necessarily for "decision making". My own view is that the distribution of control does not lead to a distribution of mind. For example, although it undoubtedly programs the grasping and manipulation involved, lower-level organization of arm actions does not participate in the "decision" of an octopus to carry separated coconut halves out onto the soft sand surface for later use as shelter (Finn, Tregenza \& Norman, 2009).

The contrast between the centralized vertebrate and the decentralized mollusk may be more quantitative than qualitative. My target article described the vertebrate spinal cord as having considerable autonomy. Pellis notes that our extensive gastrointestinal system is separate from the voluntary motor one, and Adamo notes that the human cerebellum has recently been found to contribute to complex cognitive reasoning. Embryological studies by Shigeno et al. (2018) show, first of all, that the cephalopods are closely related not to the gastropods with their distributed paired ganglia but to the amphineurans with their cordlike early embryonic nervous system. The developmental model of the cephalopod nervous system may thus be similar to the cordal one of the vertebrates and the arthropods, and the brachial arm nerve cords similar to the human spinal cord. Who knew? we had to wait for the embryologists. Octopuses, like humans, function as a single unified organism despite having many different brain areas. Perhaps in both the human and the octopus, the level of behavior is unified, although the underlying brain appears not to be. For example, lateral specialization to some extent appears to be common in bilateral brains across several phyla (Shillicock et al. 2019), yet the behavior is not laterally driven. Porcher simply says that: "there is an ' $\mathrm{I}$ ', a self-serving awareness" and the octopus "behaves as if it is centrally controlled".

It is not that there is nothing to be learned by evaluating the octopus's combination of neural organization, mind and intelligence. Cephalopods are not vertebrates; their intelligence has clearly not evolved similarly to ours (Packard). Carls-Diamante points out that our views of cognition are biased towards vertebrates; the octopus challenges the vertebrate-based explanations of cognitive functioning. Aitken writes that our "anthropocentric generalizations will be of limited use in understanding cephalopod cognition", Vonk that selection will generate different solutions to similar problems in the two groups, and Pellis that these findings generate a major challenge to our vertebrate perspective. This is all especially true because the prevailing view is that high intelligence is assumed to evolved to solve social problems, not environmental ones. This is clearly not true for the non-social or minimally social cephalopods (Guerra). Lee urges us "to re-examine our very primate-centric concept of mind, memory and the consequences of sociality and a long, slow life history for intelligence". One hopes that this will open the door for a wider and truly comparative psychological view of intelligence, as new information about complex behavior in animals such as fish and insects (Vonk) indicates we must.

5. How may we use this information in the discussion of welfare? This presentation of octopuses as mindful and sensitive raises more than just theoretical concerns. The Cambridge Declaration on Consciousness opened our understanding to the possibility that, having consciousness, cephalopods deserve ethical consideration. While welfare concerns have been extended to cephalopods in research in Canada since 1991, and are present in a few other countries as well, it was only when the European Union decided that cephalopods deserved 
ethical consideration in a variety of situations (Smith et al. 2013) that our awareness of the welfare of these animals came into wider consideration. As Browning points out, husbandry standards for cephalopods are in their infancy (although see Fiorito et al. 2015 for European information and the exemplary AITAG 2014 treatment of aquarium care standards for the giant Pacific octopus, Enteroctopus dofleini). Standards for care and treatment of all invertebrates are noticeably absent in the United States. King \& Marino note that the Marine Biological Laboratory in Woods Hole is scaling up its efforts to develop cephalopods as models for manipulative and invasive studies - after all, in the US, there are no demands for ethical consideration of this group. Jacquet, Franks \& Godfrey-Smith point out that researchers from several different countries are hoping to develop octopus "farming", with practices that go against the welfare of these probably sentient animals. The recent publication of the book The Welfare of Invertebrate Animals (Carere \& Mather 2019) will give us much-needed information about how we will carry out protection of not just cephalopods but also many of the other invertebrate groups who, after all, constitute $98 \%$ of the animals on the planet. We need more voices asking for good welfare for more animals; as Jones (2013) notes, current animal welfare policies lag behind or even ignore the science in animal sentience and cognition, especially in the United States. Noel-Guery states that among the criteria for sentience in animals is pain. Whether animals of any group feel pain is a subject of considerable controversy (see Key 2016 and accompanying commentaries in a recent issue of this journal).

6. What are the next steps? As several commentators discussed, one of the problems in trying to understand the behavior and minds of not just octopuses but all cephalopods is a lack of information. This is especially true about field observations: Although oceans make up 3/5 of the surface of the planet and much more of the habitable volume, many areas are inaccessible to human observers. Perhaps future commentators on this exchange will be able to propose observable conditions and testable hypotheses as Bueno-Guerra and Amici (2018) did in their advice for testing cognition in a collection of "non-standard" animals, including the octopus. One approach comes to my mind: we believe that octopuses do not process visual information exactly as mammals do. Feng, Chouinard, Howell \& Bennett (2017) recently evaluated the susceptibility of animals to visual geometric illusions. All the subjects they found were vertebrates (except the bees) and most were mammals: How would an octopus respond to these stimuli? Other suggestions for situations to test the octopus mind are welcome.

\section{References}

Adamo, S. (2019). Octopus: Multiple minds or just a slow thinker? Animal Sentience 26(23). Aitken, K. J. (2019). Are our ideas about octopus life too anthropomorphic to help? Animal Sentience 26(11).

Amodio, P. (2019). Octopus intelligence: The importance of being agnostic. Animal Sentience 26(20).

AZA Aquatic Invertebrate Taxon Advisory Group (AITAG). (2014). Giant Pacific Octopus (Enteroctopus dofleini) care manual. Silver Springs, MD: Association of Zoos and Aquariums. 
Browning, H. (2019). What is good for an octopus? Animal Sentience 26(7).

Bueno-Guerra, N. \& Amici, F., Eds. (2018). Field and laboratory methods in animal cognition. Cambridge, UK: Cambridge University Press.

Carere, C. \& Mather, J. A. (2019). The welfare of invertebrate animals. Cham, Switzerland: Springer series on Animal Welfare.

Carls-Diamante, S. (2017). The octopus and the unity of consciousness. Biology and Philosophy, 32, 1269-1287.

Carls-Diamante, S. (2019). The octopus mind: Implications for cognitive science. Animal Sentience 26(17).

Corcoran, A. W. (2019). Cephalopod molluscs, causal models, and curious minds. Animal Sentience 26(13).

Correia Caeiro, C. (2019). What we don't know about cephalopods and how to define it. Animal Sentience 26(22).

Favela, L. H. (2019). Octopus Umwelt or Umwelten? Animal Sentience 26(2).

Feng, L. C., Chouinard, P. A., Howell, T. J. \& Bennett, P. C. (2017). Why do animals differ in their susceptibility to geometrical illusions? Psychonomic Bulletin and Review, 24, 262276.

Finn, J. K., Tregenza, T. \& Norman, M. D. (2009). Defensive tool use in a coconut-carrying octopus. Current Biology, 19, 1029-1030.

Fiorito, G. et al. (2014). Cephalopods in neuroscience: Regulations, research, and the 3Rs. Invertebrate Neuroscience, 14, 13-36.

Ginsberg, S. \& Jablonka, E. (2019). The evolution of the sensitive soul. Cambridge, MA: MIT Press.

Godfrey-Smith, P. (2019). Octopus experience. Animal Sentience 26(18).

Grasso, F. W. (2014). The octopus with two brains: how are distributed and central representations integrated in the octopus central nervous system? In A-S. Darmaillacq, L. Dickel \& J. A. Mather, Eds., Cephalopod cognition. Cambridge, UK: Cambridge University Press, pp. 94-124.

Guerra, A. (2019). The ingenuity of cephalopods. Animal Sentience 26(5).

Gutfreund, Y. (2019). Who needs a mind when you have thousands of fingers? Animal Sentience 26(3).

Gutnick, T., Byrne, R., Hochner, B. \& Kuba, M. (2011). Octopus vulgaris uses visual information to determine the location of its arms. Current Biology, 21, 460-462.

Jacquet, J., Franks, B. \& Godfrey-Smith, P. (2019). The octopus mind and the argument against farming. Animal Sentience 26(19).

Jones, R. C. (2013). Science, sentience, and animal welfare. Biological Philosophy, 28, 1-30.

Key, B. (2016). Why fish do not feel pain. Animal Sentience 3(1).

Kier, W. M. \& Smith, K. K. (1985). Tongues, tentacles and trunks: The biomechanics of movement in muscular-hydrostats. Zoological Journal of the Linneaen Society, 83, 307324.

King, B. J. \& Marino, L. (2019). Octopus minds must lead to octopus ethics. Animal Sentience 26(14).

Lee, P. L. (2019). Are octopuses special? Mind, sociality and life history. Animal Sentience 26(10).

Mallatt, J. (2019). The octopus: A beautiful (but disorganized) "mind". Animal Sentience 26(8). 
Mather, J. A. (2019). What is in an octopus' mind? Animal Sentience 26(1).

Mehrkam, L. R. (2019). A behavior analytic approach to understanding octopus "mind". Animal Sentience 26(12).

Noel-Guery, A. (2019). Octopus sentience: Three criteria. Animal Sentience 26(24).

Packard, A. (2019). Keeping hold of Nurse. Animal Sentience 26(21).

Pellis, S. (2019). The 'Thing' from this world. Animal Sentience 26(9).

Porcher, I. F. (2019). The perfecting of the octopus. Animal Sentience 26(15).

Schnell, A. \& Vallortigara, G. (2019). 'Mind' is an ill-defined concept: Considerations for future cephalopod research. Animal Sentience 26(16).

Schwartz, B. L. (2019). A community of minds. Animal Sentience 26(4).

Shettleworth, S. J. (2010). Cognition, evolution, and behavior. Oxford, UK: Oxford University Press.

Shigeno, S., Andres, P. L. R., Ponte, G. \& Fiorito, G. (2018). Cephalopod brains: An overview of current knowledge to facilitate comparison with vertebrates. Frontiers in Physiology, 9 (952).

Shillicock, R., Thomas, J. \& Bailes, R. (2019). Mirror neurons, prediction and hemispheric coordination: The prioritizing of intersubjectivity over 'intrasubjectivity'. Axiomathes, 29, 139-153.

Smith, J. A., Andrews, P. L. R., Hawkins, P., Louhimies, S., Ponte, G. \& Dickel, L. (2013). Cephalopod research and EU Directive 2010/63/EU: Requirements, impacts and ethical review. Journal of Experimental Marine Biology and Ecology, 447, 31-45.

Vonk, J. (2019). Octopi-ing a unique niche in comparative psychology. Animal Sentience 26(6).

Wells, M. J. (1978). Octopus: Physiology and behavior of an advanced invertebrate. London, UK: Chapman and Hall. 